\title{
Korean Paddy Soil Microbial Community Analysis Method Using Denaturing Gradient Gel Electrophoresis
}

\author{
Myeongeun Choe $\cdot$ Sung-Jun Hong $\cdot$ Jong-Hui Lim $\cdot$ Yunyoung Kwak • \\ Chang-Gi Back · Hee-Young Jung · In-Jung Lee · Jae-Ho Shin*

\section{Denaturing gradient gel electrophoresis를 이용한 한국의 논 토양 미 생물 다양성 분석 방법}

최명은 · 홍성준 · 임종희 · 곽윤영 · 백창기 · 정희영 · 이인중 · 신재호*

Received: 11 December 2012 / Accepted: 21 February 2013 / Published Online: 30 June 2013

(C) The Korean Society for Applied Biological Chemistry 2013

\begin{abstract}
Soil microbes are important integral components of soil ecosystem which have significant and diverse role in organic matter decomposition, nitrogen cycling, and nitrogen fixation. In this study an effective denaturing gradient gel electrophoresis (DGGE) method was employed for paddy soil microbial diversity survey. For optimum paddy soil microbial DNA extraction, different methods such as Lysis buffer, skim milk bead, sodium phosphate buffer, Epicentre Soil Master DNA extraction kit (Epicentre, USA) and Mo Bio Power Soil DNA kit (MO BIO, USA) methods were utilized. Among all the method, using Mo Bio Power Soil kit was most effective. DGGE analysis of Bacteria was carried out at $6 \%$ polyacylamide gel and $45-60 \%$ denaturing gradient in the optimal conditions. Whereas DGGE analysis of fungi was done at $6 \%$ polyacrylamide gel and $45-80 \%$ denaturing gradient in the optimal conditions. By applying the above assay, it was found that variation within the microbial community of paddy soil occurs by a factor of time. DGGE assay used in this study through for a variety of soil microbial analysis suggests the potential use of this method.
\end{abstract}

M. Choe

Gumi Floricultural Experiment Station, Gyeongsangbuk-do Agricultural Research \& Extension Services, Gumi 730-831, Republic of Korea

S. -J. Hong · J. -H. Lim · Y. Kwak · C. -G Back · H. -Y. Jung · I. -J. Lee · J. H. Shin

School of Applied Biosciences, Kyungpook National University, Daegu 702-701, Republic of Korea

*Corresponding author (J. -H. Shin: jhshin@knu.ac.kr)
Keywords denaturing gradient gel electrophoresis (DGGE) paddy soil microbial community

\section{서 론}

다양하고 복잡한 토양 생태계를 구성하는 주요 요소인 토양 미 생물은 지구의 유기물이나 무기물의 순환에 없어서는 안 되는 매우 중요한 존재이다. 토양 미생물들 간의 상호작용이나 토양 미생물과 식물, 토양 미생물과 토양 간의 상호작용은 토양의 생 물, 물리, 화학성에 크게 영향을 미친다. 이러한 토양 미생물의 군집을 이해하는 것은 토양 생태 및 농업 환경의 이해와 관리 에 필수적이다(Paul과 Clark, 1989; Hawksworth, 2001; Straatsma 등, 2001; Torsvik 등, 2002). 토양 미생물의 군집 연구를 위해 과거에는 배양 의존적인 방법이 주로 사용되었으나, 배양 가능 한 미생물을 실험 대상으로 할 경우에는 배양에 오랜 시간이 걸릴 뿐만 아니라 인공 조건에서의 배양으로는 온도 변화, 습 도 변화, $\mathrm{pH}$ 변화, 생물 상호작용과 같은 토양의 배양 환경 요 인을 충분히 반영할 수 없다는 단점이 있다. 근래에는 토양 환 경에 존재하는 세균 중 $1 \%$ 이하 만이 배양 가능하다는 것이 밝혀지면서 인공적인 배양 과정을 거치지 않고 시료에서 토양 미생물의 핵산을 바로 분석하여 토양 미생물의 군집을 분석하 는 연구가 시도되고 있다(Schabereiter-Gurtner 등, 2001). 토양 미생물에서 직접 특정한 연구 목적의 $\mathrm{DNA}$ 와 $\mathrm{RNA}$ 를 추출하여 군집을 분석할 경우에는 배양이 불가능하거나 어려운 미생물 뿐 만 아니라 상대적으로 낮은 농도로 분포하기 때문에 배양법에 의해서는 간과되기 쉬운 미생물까지 탐지 할 수 있는 장점이 있다(Jiang 등, 2007).

이렇게 토양 환경에 존재하는 미생물의 핵산을 직접 탐구하 는 방법으로는 여러 가지가 제시되고 있다. 그 중에서도 특히 
genetic fingerprinting 기술을 기반으로 하는 Denaturing Gradient Gel Electrophoresis (DGGE) 방법은 미생물의 16S RNA 유전 자 가닥 간의 염기서열 차이로 인해 발생하는 고유한 $\mathrm{Tm}$ 값의 차이를 이용하여 서로 다른 미생물의 $16 \mathrm{~S}$ RNA 유전자를 이중 가닥을 단일가닥으로 풀어주는 변성제가 연속되는 농도 차이로 함유된 DNA 전기영동 gel 상에서 분리하고 관찰하는 방법이다 (Muyzer 등, 1993). 이 방법은 높은 효율로 많은 시료를 동시 에 분석할 수 있다는 장점이 있어서 일반적으로 미생물 다양성 연구에 많이 쓰이는 분자생물학적 기술로서 토양 뿐만 아니라 (Wang 등, 2004), 하천(Araya 등, 2003), 곤충(Reeson 등, 2003), 식물(Boon 등, 2002), 음식(Ercolini, 2004)에 이르기까지 다양한 환경 시료로부터의 미생물 분석에 적용되고 있다. 그러 나, DGGE 법에 의한 미생물 다양성 연구는 원 시료로부터의 DNA 추출방법, PCR증폭 및 분석 방법에 의해 많은 영향을 받 는다고 알려져 있으며, 특히 토양 시료에는 자체에 함유된 무 기염류나 humic acid와 같은 matrix의 간섭 때문에 핵산 만을 순수하게 추출하는 것이 힘들다는 보고가 있다(Mills 등, 2003; Williamson 등, 2011). 서양 연구자에 의한 토양 미생물 핵산 추출은 주로 사토(Sand)나 양토(Loam) 계열에서 활발히 이루어 졌으며 아시아에 분포된 논 토양과 같은 식토(Clay) 혹은 식양 토(Clay loam)에서의 연구는 많이 찾아 볼 수 없다.

본 연구에서는 한국 논 토양의 미생물 분포 관찰에 DGGE 방법을 적용하기 위해 몇 가지 토양 DNA 추출법을 시행하고 이들 시료로 행해진 DGGE 결과를 분석하여 가장 안정적인 핵 산 추출 방법을 탐구하였고 실제로 이 방법을 이용하여 논 토 양 미생물의 군집을 DGGE 방법으로 관찰, 분석하였다.

\section{재료 및 방법}

토양 시료 및 토양 성분 분석. 실험에 사용된 토양은 경상북도 군위군(위도 $36^{\circ} 6^{\prime} 8^{\prime \prime}$, 경도 $\left.128^{\circ} 37^{\prime} 11^{\prime \prime}\right)$ 에서 3 년 이상 우렁이 농 법을 시행해온 친환경 재배지의 논 토양을 사용하였다. 토양 채 취를 위하여 $5 \mathrm{~cm}$ 깊이의 표토를 제거한 후 깊이 $5-20 \mathrm{~cm}$ 까지 의 토양을 약 $100 \mathrm{~m}^{2}$ 넓이의 대상 논의 -아홉군데 이상의 부위 로부터 $100 \mathrm{~g}$ 이상이 되게 취하였으며, 채취한 토양은 즉시 하 나로 잘 섞어 시료백에 넣고 보관하며 원 시료로 사용하였다. 또한, 채취한 토양의 토성을 확인하기 위해 상기에서 채취한 토 양 시료를 실험실에서 7일간 풍건하고 잘게 부수어 $2 \mathrm{~mm}$ 체를 통과시킨 것을 화학성분 분석에 사용하였다. 화학성분 분석은 농촌진흥청 농업과학기술원 토양 및 식물체 분석법(NIAST, 2000)을 적용하였다.

토양 DNA의 추출. 토양으로부터 DNA를 추출하기 위해 토양 $\mathrm{DNA}$ 추출을 위해 일반적으로 많이 사용되고 있는 방법들을 사 용하였다. 첫 번째로 동결과 비등(freezing and boiling)을 반복 하여 토양 미생물 세포를 파괴하고 DNA를 추출해내는 "Lysis buffer method" (Vazquez-Marrufo 등, 2002)는 먼저 $3 \mathrm{~g}$ 의 토 양을 액체 질소로 얼리고 막자 사발로 곱게 갈아준 다음 $10 \mathrm{~m}$ 의 lysis buffer $(100 \mathrm{mM}$ Tris- $\mathrm{HCl}(\mathrm{pH} 8.5), 50 \mathrm{mM}$ EDTA, $50 \mathrm{mM} \mathrm{NaCl}, 10 \% \mathrm{SDS}(\mathrm{w} / \mathrm{v}))$ 를 넣고 1 분 동안 강하게 교반 하였다. 여기에 $10 \mathrm{~mL}$ 의 benzyl chloride를 넣고 3 분 동안 교반 하고 $65^{\circ} \mathrm{C}$ 에서 15 분 동안 진탕하였다. 여기에 $10 \mathrm{~mL}$ 의 chloroform 을 넣고 1 분 동안 교반한 뒤 얼음물에 넣어 10 분 동안 정치하 였다. 이후 $8,500 \times \mathrm{g}$ 에서 15 분 동안 원심 분리한 후 동량의 차
가운 isopropanol을 넣어주고 $-20^{\circ} \mathrm{C}$ 에서 15 분 동안 정치 후 다 시 $8,500 \times \mathrm{g}$ 에서 15 분 동안 원심 분리하고 pellet을 $70 \%$ ethanol로 세척한 다음 말린 뒤 최종적으로 $50 \mu \mathrm{L}$ 의 TE buffer (pH 8.0)에 현탁하였다. 두 번째 방법으로는 skim milk bead를 이용해 분쇄하는 물리적 방법과 세포막 소수성 물질을 용해시 키기 위해 SDS를 첨가하는 화학적 방법을 병용한 "Skim milk with SDS buffer method" (Yeates 등, 1998)이다. 토양 $0.25 \mathrm{~g}$ 을 액체 질소로 얼리고 막자 사발로 곱게 갈아준 다음 $0.5 \mathrm{~mL}$ 의 skim milk powder solution $\left(0.1 \mathrm{~g}\right.$ in $\left.25 \mathrm{~mL} \mathrm{H} \mathrm{H}_{2} \mathrm{O}\right)$ 에 녹인 뒤 교반하였다. 토양과 debris의 제거를 위하여 $12,000 \times \mathrm{g}$ 로 10 분간 원심 분리한 다음 상등액에 $2 \mathrm{~mL}$ 의 $\mathrm{SDS}$ extraction buffer $(0.3 \%$ SDS, $0.14 \mathrm{M} \mathrm{NaCl}, 50 \mathrm{mM}$ sodium acetate $(\mathrm{pH}$ 5.1))를 첨가하고 교반하였다. 여기에 동량의 water-saturated phenol을 넣어준 뒤 2 분 동안 교반한 다음 $12,000 \times \mathrm{g}$ 로 10 분 동안 원심 분리하였다. 원심 분리 상등액에 2.5 배의 ethanol을 첨가하고 $-20^{\circ} \mathrm{C}$ 에서 3 시간 동안 방치한 뒤 $4^{\circ} \mathrm{C}$ 에서 원심 분리 하여 $\mathrm{DNA}$ 를 획득한 다음 최종적으로 $0.3 \mathrm{~mL}$ 의 $\mathrm{TE}$ buffer $(\mathrm{pH} 8.0)$ 에 현탁하였다. 세 번째는 동결 비등, bead의 두 가지 물리적 방법과 세포벽 파괴에 lysozyme을 처리하는 "Sodium phosphate buffer method" (Grosskopf 등, 1998)이다. 먼저 $1 \mathrm{~g}$ 의 토양에 $1 \mathrm{~mL}$ 의 $0.12 \mathrm{M}$ sodium phosphate buffer $(\mathrm{pH} 8.0)$ 를 넣어 잘 혼합한 뒤 얼리기와 녹이기를 3 번 반복하였다 $(-70$ ${ }^{\circ} \mathrm{C}$ for $2 \mathrm{~min}, 65^{\circ} \mathrm{C}$ for $\left.2 \mathrm{~min}\right)$. 여기에 $5 \mathrm{mg}$ 의 lysozyme을 섞어준 다음 $37^{\circ} \mathrm{C}$ 에서 1 시간 동안 incubation하고 sodium dodecyl sulfate (SDS)를 최종농도 $2 \%$ 가 되도록 넣어준 다음 $60^{\circ} \mathrm{C}$ 에서 다시 10 분 동안 incubation하였다. 여기에 같은 양의 $0.1 \mathrm{~mm}$ glass beads (BioSpec Products, Bartlesville, Okla, USA) 를 넣어 한 번에 80 초씩 세 번 교반한 다음 $13,000 \times \mathrm{g}$ 에서 10 분 동안 원심분리하고 상등액을 취하여 같은 양의 isopropanol 을 넣고 침전시켜 최종적으로 $100 \mu \mathrm{L}$ 의 $\mathrm{TE}$ buffer $(\mathrm{pH}$ 8.0)에 현탁하였다. 네 번째로 토양을 고온의 계면활성제(detergent)로 처리하여 전체 핵산을 용출시킨 다음 DNA specific anion exchange resin이 채워진 spin column으로 DNA만을 분리해 내는 "Epicentre SoilMaster DNA extraction kit" (Epicentre, Madison, $\mathrm{WI}, \mathrm{USA})$ 는 제조사의 방법을 사용하여 실시하였다. 마지막 다 섯 번째로 "PowerSoil DNA Isolation kit" (MO BIO, Carlsbad, CA, USA)는 bead beating법으로 토양 미생물의 세포벽과 세포 막을 파괴하고 silica spin filter를 통해 DNA를 흡착, 정제하는 방법으로 제조사의 방법을 따라 실시하였다.

DGGE-PCR. 토양 미생물의 RNA 유전자를 증폭하기 위해 세 균과 진균의 경우 모두 $16 \mathrm{~S} \mathrm{rRNA}$ 와 $18 \mathrm{~S}$ rRNA gene 영역을 증폭하였다. $16 \mathrm{~S}$ rRNA gene 영역의 증폭을 위한 primer는 GCclamp인 63-G(5'-CGC CCG CCG CGC GCG GCG GGC GGG GCG GGG GCA CGG GGG G-3')와 518R(5'-CAG GCC TAA CAC ATG CAA GTC TTA CCG CGG CTG CTG G-3')을 사용하였고(Muyzer 등, 1993), PCR 반응을 위한 조건은, $95^{\circ} \mathrm{C}$ 에서 Pre-denaturation 2 분, $95^{\circ} \mathrm{C}$ 에서 denaturation 30 초, $54^{\circ} \mathrm{C}$ 에서 annealing 30 초, $72^{\circ} \mathrm{C}$ 에서 extension 1 분 과정을 30 cycle 반복하였다. $18 \mathrm{~S} \mathrm{rRNA}$ gene 영역의 증폭을 위한 primer는 FR1-GC (5'-CCC CCG CCG CGC GCG GCG $\mathrm{GGC}$ GGG $\mathrm{GCG}$ GGG $\mathrm{GCA}$ CGG $\mathrm{GCC}$ G-3')와 $\mathrm{FF} 390$ (5'-AIC CAT TCA ATC GGT AIT CGA TAA CGA ACG AGA CCT-3') 을 각각 사용하였고(Vainio and Hantula, 2000), $\mathrm{PCR}$ 반응 조건은 $16 \mathrm{~S} \mathrm{rRNA}$ gene과 동일하게 수행하였다. 
PCR 산물은 $0.8 \%$ agarose gel에서 전기영동하여 ethidium bromide로 염색한 후 UV transilluminator 상에서 확인하였다. DGGE 분석. $\mathrm{PCR}$ 로 증폭된 산물은 $\mathrm{DGGE}$ 분석을 하기 위해 서 denaturing gel은 세균 $7.5 \%(\mathrm{v} / \mathrm{v})$, 진균 $6 \%(\mathrm{v} / \mathrm{v})$ 의 polyacrylamide gel (acrylamide- $\mathrm{N}$, N-methylene bisacrylamide, $37.5: 1$ )에 formamide와 urea 변성제를 세균 $45-50 \%$, 진균 35$60 \%$ 까지 농도구배가 형성되도록 첨가하여 제작하였다. 위의 방 법으로 제작된 gel에 PCR 증폭산물을 loading하여 $1 \times \mathrm{TAE}$ buffer $(40 \mathrm{mM}$ Tris, $20 \mathrm{mM}$ acetic acid, $1 \mathrm{mM}$ EDTA, pH 8.0 )의 완충용액에서 $60^{\circ} \mathrm{C}, 50 \mathrm{~mA}$ 로 20 시간 동안 전기영동하였 다. 전기영동 후에 denaturing gradient gel은 ethidium bromide 로 염색한 후 UV transilluminator 상에서 확인하였다. DGGE fingerprint 유사성은 GelCompar II (Applied Maths, Kortrijk, Belgium)를 사용하여 분석하였고 band 유사도는 Jaccard coefficient와 Pearson coefficient로 표현하였다. 종 다양성은 Shannon Index 값을 아래의 식을 이용하여 산출하였다.

$$
H=-\Sigma\left[\mathrm{p}_{i} \times \ln (\text { Schabereiter-Gurtner et al.) }]\right.
$$

$\mathrm{p}_{i}$ is the proportion of the community represented by species $i$, and the summation is over all species. $H$ represents the uncertainty in predicting the species of an individual chosen at random (Ludwig and Reynolds, 1988).

\section{결과 및 고찰}

토양 분석. 본 연구에서 사용된 논 토양의 주요 물리 화학성을 재료 및 방법에서 설명한 것과 같은 방법으로 분석하였다. 토 양 축소모형에 사용된 토양의 $\mathrm{pH}$ 는 6.6 으로 중성 범위로 확인 되었고, 전기 전도도는 $0.22 \mathrm{ds} / \mathrm{m}$ 이었다. 유기물 함량을 Tyurin 법(Schollenberger, 1927)으로 측정한 결과는 $22 \mathrm{~g} / \mathrm{kg}$ 으로 확인되 었으며 토양의 최종 토성은 식양토(clay loam)로 확인되었다.

DGGE 분석을 위한 토양 DNA 추출 방법. DGGE 분석을 위 한 $\mathrm{gDNA}$ 확보를 위해 논 토양으로부터 다양한 방법으로 $\mathrm{DNA}$ 추출을 시도하였다. Lysis buffer method를 이용하여 추출한 결 과 DNA 절대량이 많이 부족한 단점을 보였고, sodium phosphate buffer method와 skim milk method를 통하여 추출된 DNA 량 은 상대적으로 많았으나 전기영동상에서 DNA 순도에 문제가 있을 때 나타나는 끌림 현상이 나타났다. Mo Bio PowerSoil kit $(\mathrm{MO} \mathrm{BIO}, \mathrm{USA})$ 추출법에서는 전기영동상 끌림이 없고 깨 끗한 DNA band를 확인할 수 있었고, DNA도 적정한 양을 얻 을 수가 있었다(데이터 미제시). 다양한 방법으로 추출된 토양 total DNA 시료 $10 \mathrm{ng}$ 을 각각 주형으로 하고 primer 63-G와 $518 \mathrm{R}$ 을 사용하여 세균의 $16 \mathrm{~S}$ RNA 유전자를 증폭한 결과 모 든 시료에서 증폭이 관찰되었으나, 특히 Mo Bio PowerSoil kit 로 추출된 $\mathrm{DNA}$ 를 template로 $\mathrm{PCR}$ 을 한 결과 primer dimer 형성이 적게 나타났고, 상대적으로 진한 $\mathrm{PCR}$ 증폭산물을 얻을 수 있었다(데이터 미제시). 또한 같은 방법으로 primer FR1-GC 와 $\mathrm{FF} 390$ 를 사용하여 진균의 $18 \mathrm{~S} \mathrm{RNA}$ 유전자를 증폭한 결과 skim milk법과 Mo Bio PowerSoil kit법으로 추출한 시료에서 상대적으로 많은 증폭이 관찰되었다. 반면 Epicentre SoilMaster DNA extraction kit로 추출한 DNA에서는 진균의 $18 \mathrm{~S}$ RNA 유전자의 증폭을 관찰할 수 없었다(데이터 미제시). 똑같이 $10 \mathrm{ng}$ 의 주형 $\mathrm{DNA}$ 를 사용하였지만 증폭 산물에 차이가 난 것으로

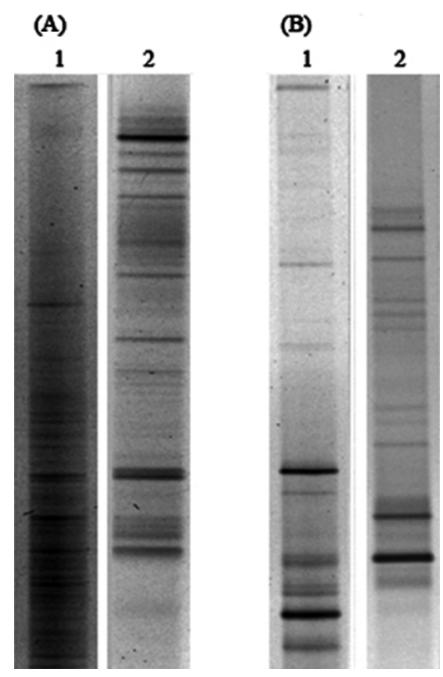

Fig. 1 Comparison of running condition applied to the 16S rRNA genes and 18s rRNA genes from paddy soil. (A) Bacteria DGGE analysis, Lane1; A $6 \%$ polyacrylamide gel with a $40 \%$ to $80 \%$ denaturing gradient Lane 2 ; A $7.5 \%$ polyacrylamide gel with a $45 \%$ to $60 \%$ denaturing gradient. (B) Fungi DGGE analysis, Lane 1; A 6\% polyacrylamide gel with a $45 \%$ to $80 \%$ denaturing gradient, Lane 2 ; A $6 \%$ polyacrylamide gel with a $35 \%$ to $60 \%$ denaturing gradient.

보아 Epicentre Soil Master DNA extraction kit (Epicentre, USA) 에서는 논 토양 내의 미생물 DNA 추출과정에서 특히 진 균에 대한 추출 효율이 낮다는 것을 알 수 있었다. 따라서 논 토양으로부터 DNA 추출 시에 Mo Bio PowerSoil kit를 사용 할 경우 세균과 진균 분석에 가장 안정적이고 재현성이 높았으 며, PCR 증폭을 위한 효율적인 DNA 추출이 가능했다.

DGGE 조건 확립. 토양 미생물의 군집 분포를 가장 확연하게 관찰할 수 있는 조건을 확립하기 위하여 여러 조건에서 $\mathrm{DGGE}$ 를 시도하였다. 세균의 DGGE를 $6 \%$ polyacrylamide gel에서 실시하였을 때에는 band 분포가 지나치게 조밀하고 주로 gel의 하부에 band가 몰리는 경향이 나타났다. 농도를 $7.5 \%$ 로 높이자 전체 gel 영역에 잘 분포된 band를 확인할 수 있었으며 또한 denaturing gradient도 통상의 방법인 40-80\%를 처리하였을 경 우 band가 gel의 한쪽에 밀집하는 현상을 보여 패턴의 분석이 용이하지 않았으나 gradient를 45-60\%로 주었을 때에는 넓은 영역에서 가장 많은 band를 분리할 수 있었다(Fig. 1A).

진균의 DGGE분석에서도 통상의 방법인 $10 \%$ polyacrylamide gel에서 실험하였을 때 band 구배가 일어났으나 위쪽에 밀집되 어 12 개의 band만 확인 가능하였다. 이에 다양한 변성제 농도 조건을 적용하여 band의 분포를 아래쪽으로 낮추었으나 역시 최대 10 여 개의 band만 확인할 수 있었다. 밀집된 굵은 band를 풀어주기 위해 polyacrylamide의 농도를 $6 \%$ 로 낮추어주었다. $6 \%$ gel 농도에 denaturing gradient를 45-80\%로 처리하였을 때 16 개의 band를 확인할 수 있었고. 아래쪽에 밀집한 굵은 band 를 풀어보고자 변성제 농도를 35-60\%로 조절한 결과 gel 상에 서 균일하게 분포하는 24 개의 band를 관찰 할 수 있었다(Fig. 1B).

추출방법에 따른 논 토양 세균의 DGGE 결과 비교. 토양으로 부터 $\mathrm{DNA}$ 를 추출할 수 있는 다섯 가지의 방법으로 얻은 논 토양 미생물 $\mathrm{DNA}$ 를 위에서 확립한 bacteria DGGE 조건에서 
(A)

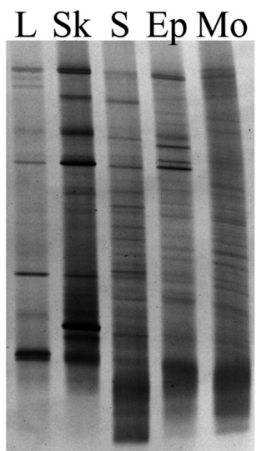

(B)

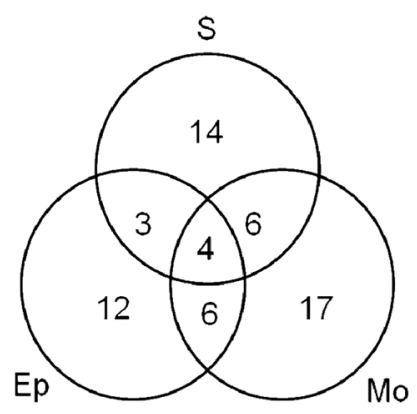

Fig. 2 Assessment of bacterial communities in paddy soil as determined by $16 \mathrm{~S}$ rRNA gene PCR-DGGE analyses on the basis of five extraction methodologies. L, soil DNA extracted by lysis buffer method; Sk, soil DNA extracted by skim milk with SDS buffer method; S, soil DNA extracted by sodium phosphate buffer method; Ep, soil DNA extracted by Epicentre SoilMaster DNA extraction kit; Mo, soil DNA extracted by Mo Bio PowerSoil DNA isolation kit. (A) DGGE profiles. (B) Venn diagrams indicating numbers of shared and method-specific bands across different extraction methods. Letters above, below, and next to the circles indicate the extraction method. Numbers in the circles and in the in the intercepts indicate numbers of method-specific and shared bands, respectively.

Table 1 DGGE band based comparisons of band richness and Shannon indices of bacterial community extracted with various methods

\begin{tabular}{lccccc}
\hline \multicolumn{1}{c}{ Index } & L & Sk & S & Ep & Mo \\
\hline Band richness & $18^{\text {a) }}$ & 22 & 29 & 28 & 35 \\
Shannon & 2.4454 & 2.6960 & 3.1712 & 2.9925 & 3.3870 \\
\hline
\end{tabular}

${ }^{a}$ Band numbers were used to estimate the richness of the target microbial groups.

시험하였다(Fig. 2A). 같은 토양에서 채취한 DNA이지만 추출 방법에 따라 그 band의 표현 양상이 확연히 다르게 나타났다. Lysis buffer method을 사용하여 추출하였을 때에는 18 개의 band가 나타나 가장 수가 적었다. Skim milk method로 추출한 토양에서는 22 개의 band가 관찰되었으며 band의 위치와 형태도 전체적으로 lysis buffer method의 경우와 유사하였으나 특정 band들이 매우 두드러지게 나타나는 것으로 보아 특정 미생물 에 편중되게 추출 효율이 높다는 것을 알 수 있었다. Sodium phosphate buffer, Epicentre SoilMaster DNA extraction kit를 (Epicentre, USA) 사용하였을 때에는 각각 27, 25개의 band가 관찰 되었지만 공통된 위치에서 나타나는 band는 7개인 것으로 미뤄보아 각각의 방법으로 추출되는 주요 미생물의 DNA가 서 로 다름을 알 수 있었다. Mo-bio PowerSoil Isolation kit를 사 용한 토양에서는 33 개의 band가 관찰 되었는데 다른 방법으로 추출한 결과와 중복되는 것을 16 개, 다른 방법으로는 표현이 되 지 않던 band 17 개를 포함하고 있었다. Band의 개수와 종 다 양성 지수를 각각 비교했을 때 Mo-bio PowerSoil Isolation kit 를 사용한 경우가 각각 33 개의 band 수, 3.3870 의 종 다양성 지수를 가지므로 가장 논 토양 미생물의 다양성 평가에 적합한 방법임을 알 수 있었다(Table 1). 다양성 지수가 3.0 이상에 해 당하는 각 추출 방법에 의한 band를 종합한 venn diagram에서 는 세 가지 방법에 의해 공통적으로 나타난 band는 4종에 불
(A)

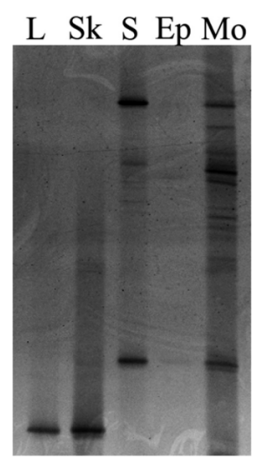

(B)

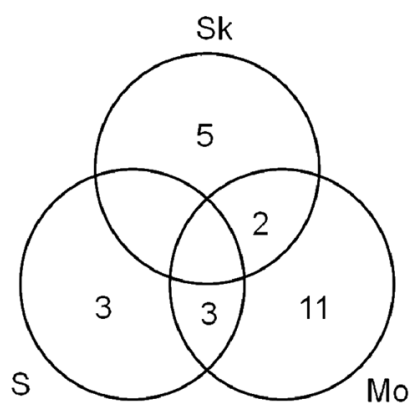

Fig. 3 Assessment of bacterial communities in paddy soil as determined by $18 \mathrm{~S}$ rRNA gene PCR-DGGE analyses on the basis of five extraction methodologies. L, soil DNA extracted by lysis buffer method; Sk, soil DNA extracted by skim milk with SDS buffer method; S, soil DNA extracted by sodium phosphate buffer method; Ep, soil DNA extracted by Epicentre SoilMaster DNA extraction kit; Mo, soil DNA extracted by Mo Bio PowerSoil DNA isolation kit. (A) DGGE profiles. (B) Venn diagrams indicating numbers of shared and method-specific bands across different extraction methods. Letters above, below, and next to the circles indicate the extraction method. Numbers in the circles and in the in the intercepts indicate numbers of method-specific and shared bands, respectively.

Table 2 DGGE band based comparisons of band richness and Shannon indices of fungal community extracted with various methods

\begin{tabular}{lccccc}
\hline \multicolumn{1}{c}{ Index } & $\mathrm{L}$ & $\mathrm{Sk}$ & $\mathrm{S}$ & $\mathrm{Ep}$ & Mo \\
\hline Band richness & $1^{\mathrm{a}}$ & 7 & 6 & 2 & 16 \\
Shannon & 0 & 1.3243 & 1.4353 & 0.6922 & 3.6524 \\
\hline
\end{tabular}

${ }^{a}$ Band numbers were used to estimate the richness of the target microbial groups.

과하였고 서로 한 번 이상 겹치는 band도 19 종에 불과하였기 때문에 미생물 개개의 존재 유무 확인은 추출 방법에 따라 크 게 영향을 받는 것을 알 수 있었다(Fig. 2B).

추출방법에 따른 논 토양 진균의 DGGE 결과 비교. 여러 가지 방법으로 추출한 논 토양 미생물 $\mathrm{DNA}$ 를 주형으로 진균의 다 양성을 검출하기 위한 진균 DGGE를 실시하였다(Fig. 3). 실험 결과 lysis buffer method, skim milk method를 사용해 추출한 산물에서는 각각 한 가지 band만 나타나 우점한 한 종의 진균 DNA만 특이적으로 추출되었음을 알 수 있다. Epicentre Soil Master DNA방법으로 추출 산물은 2개의 band만 증폭되었으며 상대적으로 증폭량이 많지 않은 것으로 보아 이 방법은 논 토 양에 존재하는 진균 $\mathrm{DNA}$ 의 추출 효율이 좋지 않음을 알 수 있었다. Skim milk method와 Sodium phosphate buffer method 를 사용하여 추출한 $\mathrm{DNA}$ 를 주형으로 한 $\mathrm{PCR}$ 산물은 각각 7 개와 6개의 band를 보여주었다. Mo Bio PowerSoil DNA Isolation kit를 사용한 주형은 16 개의 PCR 산물의 band를 나타 내었으며 종 다양성 지수 3.6524를 나타내었으므로 논 토양 진 균의 추출에 가장 효과적인 방법인 것을 알 수 있었다(Table 2). 진균의 DGGE 분석을 위해서는 이외의 방법은 모두 종 다양성 지수가 2 미만으로 낮게 나타났고 6종 이상의 band를 보여준 각각의 방법을 venn diagram으로 분석한 결과에서도 공통된 band는 나타나지 않았으므로 특히 진균의 $\mathrm{DNA}$ 를 이용한 종 다 


\section{(A) Pearson type}

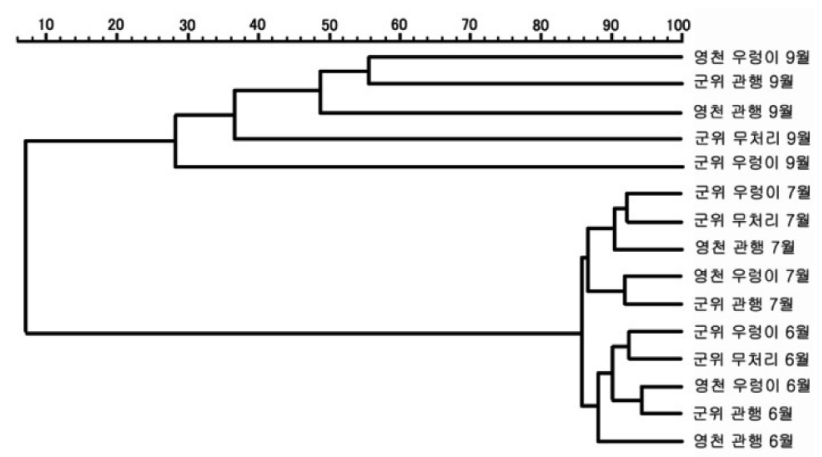

(B) Jaccard type

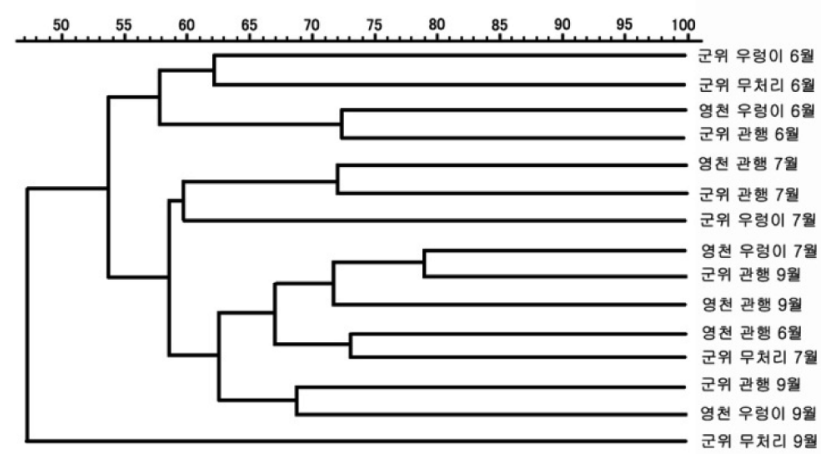

Fig. 4 Genetic similarity of bacterial community profiles based on DGGE band patterns. Change in the bacterial diversity of paddy soil was shown the impact of the time than farming.

양성 분석은 추출 방법에 따라 크게 영향을 받는 것을 알 수 있었다(Fig. 3B).

DGGE 실험 방법 적용 및 유사도 분석. 실제 논 토양에 적용 하여 시간별, 농법별 차이 구분 가능성을 확인하였다. 세균의 DGGE band 유형을 비교한 결과 각 band의 두께, 즉 우점종의 우점도를 기초로 유사성을 나타내는 Pearson 분석법에서는 6월, 7월, 9월의 시간에 따라 그룹을 확연하게 이루었고, 각 band의 위치를 기초로 우점종의 구성의 유사성을 나타내는 Jaccard 분 석법에서 역시 영천 우렁이 7월, 영천 관행 6월 과 군위 무처 리 7월을 제외하고는 시간에 따라 높은 유사성을 보였다. 따라 서 논 토양 미생물의 우점 정도 및 우점종 구성은 농법이나 위 치의 차이 보다는 계절이 가장 큰 요인임을 알 수 있었다(Fig. 4). 진균의 DGGE band 유형을 비교한 결과 Pearson 분석법에 서는 군위 우렁이 9월 토양이 다른 농법의 6월 토양과 유사하 게 나온 것을 제외하고는 우점종의 우점도가 시간 별로 높은 유사성을 가졌고, 우점종의 구성의 유사성을 나타내는 Jaccard 분석법에서 지역, 시간과 농법으로 유사도를 규정지을 수 없어 진균의 우점종 구성의 변화는 농법, 위치, 계절적 요인과는 별 개의 요소로 인해 일어났음을 추측해 볼 수 있었다(Fig. 5). 본 연구를 바탕으로 같은 토성을 가진 토양이지만 온도, 시간 및 재배 방법에 따른 미생물 군집 변화를 DGGE 방법을 사용하여 감지할 수 있음을 알 수 있다. 또한 사용된 DGGE 분석 방법 을 이용하여 토양 뿐만 아니라 다양한 환경 샘플을 활용하여 미생물 다양성을 분석할 수 있을 것으로 사료된다.
(A) Pearson type

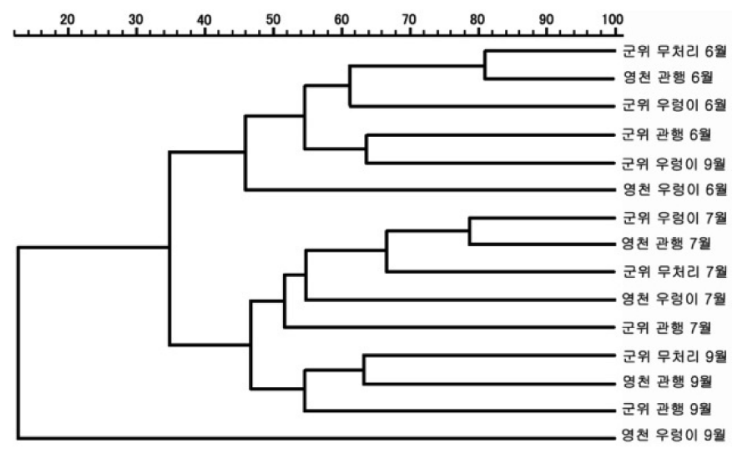

(B) Jaccard type

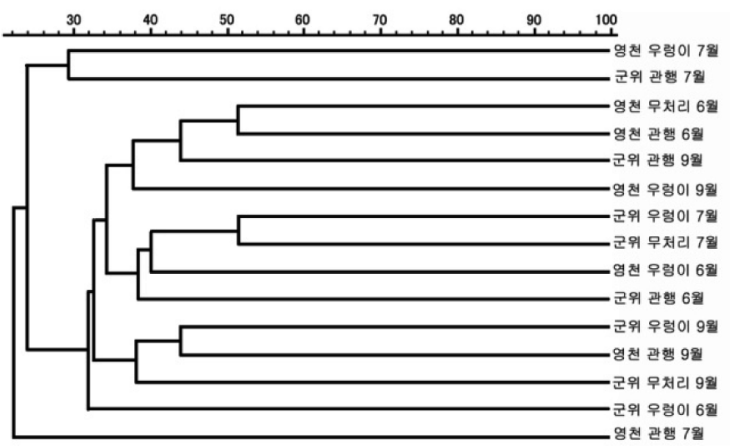

Fig. 5 Genetic similarity of fungal community profiles based on DGGE band patterns. Change in the fungal diversity of paddy soil was shown the impact of the time than farming.

\section{초 록}

현재 토양 생태에서 토양미생물은 유기물 분해, 질소 순환, 식 물의 질소 이용 등중요한 역할을 하고 있어, 토양 내 미생물 다 양성을 분석하기 위한 연구는 지속적으로 진행되어 오고 있다. 본 연구에서는 논 토양의 미생물 생태 다양성을 조사하기 위한 효과적인 방법으로 denaturing gradient gel electrophoresis (DGGE)를 적용하고자 본 연구를 수행하였다. 논 토양 미생물 의 DNA를 분리하기 위하여 lysis buffer method, skim milk bead method, sodium phosphate buffer method, Epicentre SoilMaster DNA extraction kit (Epicentre, USA), Mo Bio PowerSoil kit (Mo Bio, USA)를 이용하여 토양 내 gDNA 최 적 추출방법을 확인하였다. 그 결과 Mo Bio PowerSoil kit를 사용하였을 때 Shannon 다양성지수가 세균 3.3870 , 진균 3.6254 으로 미생물 다양성 분석시에 가장 효과적이었다. DGGE 분석을 위한 조건은 세균의 경우 $6 \%$ polyacylamide gel, $45-$ $60 \%$ denaturing gradient였고, 진균의 경우 $6 \%$ polyacrylamide gel, 45-80\% denaturing gradient에서 최적 분석조건을 보였다. 위의 분석법을 적용하여 논 토양내의 미생물 군집의 변화를 살 펴보면 시간의 변화 요인에 의해 미생물 변화가 일어나는 것을 알 수 있었다. 본 연구에서 사용된 DGGE 분석법을 통해 논 토양 미생물의 분석 가능성을 제시 할 수 있었다.

Keywords 논 토양 - 미생물 다양성 - 변성 구배 젤 전기영동 
감사의 글 본 연구는 환경부 “차세대 에코이노베이션사업”으로 지원 받은 연구이며, 연구비 지원에 감사 드립니다.

\section{References}

Araya R, Tani K, Takagi T, Yamaguchi N, and Nasu M (2003) Bacteria activity and community composition in stream water and biofilm from an urban river determined by fluorescent in situ hybridization and DGGE analysis. FEMS Microbiol Ecol 43, 111-9.

Boon N, Windt W, Verstraete W, and Top EM (2002) Evaluation of nested PCR-DGGE (denaturing gradient gel electrophoresis) with groupspecific 16S rRNA primers for the analysis of bacterial communities from different wastewater treatment plants. FEMS Microbiol Ecol 39, $101-12$.

Ercolini D (2004) PCR-DGGE fingerprinting: novel strategies for detection of microbes in food. J Microbiol Methods 56, 297-314.

Grosskopf R, Janssen PH, and Liesack W (1998) Diversity and structure of the methanogenic community in anoxic rice paddy soil microcosms as examined by cultivation and direct $16 \mathrm{~S}$ rRNA gene sequence retrieval. Appl Environ Microbiol 64, 960-9.

Hawksworth DL (2001) The magnitude of fungal diversity: the 1.5 million species estimate revisited. Mycol Res 105, 1422-32.

Jiang H, Liao B, Ren X, Lei Y, Mace E, Fu T et al. (2007) Comparative assessment of genetic diversity of peanut (Arachis hypogaea L.) genotypes with various levels of resistance to bacterial wilt through SSR and AFLP analyses. J Genet Genomics 34, 544-54.

Ludwig JA and Reynolds JF (1988) Statical ecology : A primer on methods and computing, p.96, J Wiley \& Sons, New York

Mills DK, Fitzgerald K, Litchfield CD, and Gillevet PM (2003) A comparison of DNA profiling techniques for monitoring nutrient impact on microbia community composition during bioremediation of petroleumcontaminated soils. J Microbiol Methods 54, 57-74.

Muyzer G, de Waal EC, and Uitterlinden AG (1993) Profiling of complex microbial populations by denaturing gradient gel electrophoresis analysis of polymerase chain reaction-amplified genes coding for 16S rRNA. Appl Environ Microbiol 59, 695-700.

NIAST (2000) In Method of soil and plant analysis. pp.103-47 National Institute of Agricultural Science and Technology (NIAST), Suwan, Korea.

Paul EA and Clark FE (1989) In Soil Microbiology and Biochemistry. Academic Press, San Diego, CA.

Reeson AF, Jankovic T, Kasper ML, Rogers S, and Austin AD (2003) Application of 16S rDNA-DGGE to examine the microbial ecology associated with a social wasp Vespula germanica. Insect Mol Biol 12, 85-91.

Schabereiter-Gurtner C, Pinar G, Lubitz W, and Rolleke S (2001) An advanced molecular strategy to identify bacterial communities on art objects. J Microbiol Methods 45, 77-87.

Schollenberger CJ (1927) A Rapid Approximate Method for Determining Soil Organic Matter. Soil Sci 24, 65-8.

Straatsma G, Ayer F, and Egli S (2001) Species richness, abundance, and phenology of fungal fruit bodies over 21 years in a Swiss forest plot. Mycoll Res 105, 515-23.

Torsvik V, Ovreas L, and Thingstad TF (2002) Prokaryotic diversity Magnitude, dynamics, and controlling factors. Science 296, 1064-6.

Vainio EJ and Hantula J (2000) Direct analysis of wood-inhabiting fungi using denaturing gradient gel electrophoresis of amplified ribosomal DNA. Mycol Res 104, 927-36.

Vazquez-Marrufo G, Vazquez-Garciduenas MS, Gomez-Luna BE, and OlaldePortugal V (2002) DNA isolation from forest soil suitable for PCR assays of fungal and plant rRNA genes. Plant Mol Biol Rep 20, 379-90.

Wang YS, Wen CY, Chiu TC, and Yen JH (2004) Effect of fungicide iprodione on soil bacterial community. Ecotoxicol Environ Saf 59, 12732.

Williamson KE, Kan J, Polson SW, and Williamson SJ (2011) Optimizing the indirect extraction of prokaryotic DNA from soils. Soil Biol Biochem 43, $736-48$.

Yeates C, Gillings MR, Davison AD, Altavilla N, and Veal DA (1998) Methods for microbial DNA extraction from soil for PCR amplification. Biol Proced Online 1, 40-7. 